DOI: https://doi.org/10.47405/mjssh.v6i9.983

\begin{tabular}{|c|c|}
\hline 4.581 & Malaysian Journal of Social Sciences and Humanities (MJSSH) \\
\hline $\begin{array}{l}\text { Malaysian Journal of } \\
\text { Social cciences and }\end{array}$ & Volume 6, Issue 9, September 2021 \\
\hline (MJ-SSH) & e-ISSN : 2504-8562 \\
\hline & $\begin{array}{l}\text { Journal home page: } \\
\text { www.msocialsciences.com }\end{array}$ \\
\hline
\end{tabular}

\title{
Stress, Emotional Eating and Food Choices Among University Students During the Covid-19
}

\author{
Shi-Hui Cheng ${ }^{1}$, Shi Ern Wong1 \\ ${ }^{1}$ School of Biosciences, Faculty of Science and Engineering, University of Nottingham Malaysia, Jalan Broga, \\ 43500 Semenyih, Selangor Darul Ehsan, Malaysia
}

Correspondence: Shi-Hui Cheng (ShiHui.Cheng@nottingham.edu.my)

\begin{abstract}
The Covid-19 pandemic has had a huge impact on stress and eating behaviours. This study aims to determine the relationship between stress, emotional eating, and food choices among university students during the Covid-19. A total of 273 university students participated in this cross-sectional study. Online self-administered questionnaires were used to determine the stress intensity, emotional eating, and eating behaviours. All statistical analyses were performed using Statistical Package for the Social Sciences (SPSS). Almost half (49.8\%) of the participants experienced high stress. In males, the high-stress group consumed sweets or sugars more frequently than the low-stress group $(p<0.05)$. In females, the high-stress group consumed more sweets or sugar and cakes or cookies but less milk products and fresh fruits than the low-stress group $(\mathrm{p}<0.05)$. Students with higher negative emotion scores consumed less cooked vegetables $(\mathrm{r}=-0.133 ; \mathrm{p}<0.05)$ whereas students with higher positive emotion scores consumed more fast food $(r=0.208 ; p<0.001)$, sweets or sugar $(r=0.139 ; p<0.05)$ and cakes or cookies $(r=0.139 ; \mathrm{p}<0.05)$. Body Mass Index (BMI) was positively correlated with negative emotions $(\mathrm{r}=0.134 ; \mathrm{p}<0.05)$, negative situations $(\mathrm{r}=0.161 ; \mathrm{p}<0.01)$, and total negative Emotional Appetite Questionnaire (EMAQ) scores ( $\mathrm{r}=0.168 ; \mathrm{p}<0.01)$. In conclusion, Covid-19 brings negative impact on stress. University students shifted food preferences from healthy foods to palatable foods and this could result in adverse health outcomes. Therefore, stress management interventions and nutrition education should be implemented to reduce stress and overcome stress-induced eating behaviour among private university students during the Covid-19.
\end{abstract}

Keywords: stress, emotional eating, eating behaviour, university students, Covid-19

\section{Introduction}

The Covid-19 pandemic has dramatically increased stress and anxiety for many people around the world (Pfefferbaum \& North, 2020). Stress is a situation whereby an individual appraises as overwhelming or threatening that would affect homeostasis (Monroe \& Cummins, 2015). In recent years there has been growing interest in the effects of prolonged stress on health. It has been well established that stress affects individuals' health through the physiological process and by altering lifestyle habits including physical activity, smoking, and dietary behaviours (Vollrath, 2001). Human studies have proven inconsistent effects on food intake patterns; leading to either hyperphagia or hypophagia (Oliver, Wardle \& Gibson, 2000; Wardle et al., 2000). Moreover, stress has been reported to alter eating behaviours, redirecting food choices to food with high palatability and calorie (Barrington et al., 2014; Torres \& Nowson, 2007; Wardle et al., 2000). Palatable foods or comfort 
foods are foods with high sugar and fat content that provide pleasure upon consumption. Stressed individuals tended to consume more palatable foods which may result in weight gain and obesity (Laitinen \& Sovio, 2002).

University students are particularly vulnerable to stress. The prevalence of stress among university students were surprisingly high across the world; the prevalence of stress was $25 \%$ in Ethiopia (Muna \& Atinkut, 2018), 27\% in Turkey (Bayram \& Bilgel, 2008) and Hong Kong (Wong et al., 2006), 49\% in India (Reddy, Menon \& Thattil, 2018) and 62\% in Egypt (Abdel Wahed \& Hassan, 2017). In Malaysia, a recent study among private university students found a prevalence rate of $40 \%$ (Cheng and Kamil, 2020). This shows that the prevalence of stress among university students in Malaysia is high even before the Covid-19. In Malaysia, the Covid-19 was first detected in January 2020 and there was a sharp increase in local Covid-19 cases in March 2020 following a religious event that took place at Sri Petaling, Kuala Lumpur. After the event, Malaysia recorded the highest number of positive Covid19 cases in South East Asia. A nationwide Movement Control Order (MCO) was declared on 18 March 2020 by the Prime Minister of Malaysia, aiming to mitigate the pandemic. University closure, quarantine, social distancing, emergency online teachings and uncertainty in the commencement of universities have significant implications on students' well-being and stress level (Aristovnik et al., 2020). Literature suggests that stress is associated with lower quality diets, lower physical activity levels, and adverse health behaviours among college and university students (Nelson et al., 2008).

Emotional eating is a major public health problem among university students and is especially prevalent among female university students. For instance, in Indonesia, the prevalence of emotional eating among female university students was 15\% (Muharrani, Achmad \& Sudiarti, 2018). Generally, emotional eating is defined as the practice of overeating in response to emotions instead of physical hunger. Traditionally, the focus has always been on negative emotions (Arnow, Kenardy \& Agras, 1995; Ganley, 1989, Lindeman \& Stark, 2001). Clinical and experimental researches have revealed that individuals especially obese individuals reported hyperphagia during negative emotions (Biasi \& Bonaiuto, 2014). However, Macht and Simons (2000) reported that positive emotions had a similar effect on food intake patterns. In addition, a recent meta-analysis found that both positive and negative emotions were associated with increased food consumption (Cardi, Leppanen \& Treasure, 2015). Therefore, the effects of positive emotions and negative emotions on eating behaviours were inconsistent.

In addition to increased food consumption, emotions have been found to alter food choices in different settings. A previous study reported that emotional eaters increased their high energy-dense food intake during stress (Oliver, Wardle and Gibson, 2000). Furthermore, a cross-sectional study conducted in the United States revealed that emotional eating was associated with increased frequency of palatable food intake among Latino adolescents (Nguyen-Michel, Unger \& Spruijt-Metz, 2007). Besides, Wallis and Hetherington (2004) revealed an association between emotional eating and increased consumption of chocolate after an ego-threatening stressor. Literature suggests that emotional eating is associated with obesity and depression (van Strien, 2018).

Previous studies have been conducted on the effect of Covid -19 pandemic and stress in other countries including the United States (Khubchandani, Kandiah \& Saiki, 2020) and China (Cao et al., 2020), and reported a significantly increased level of stress among university students during the Covid-19 pandemic. However, we found no studies that have examined the pandemic related stress and dietary habits among university students in Malaysia. Therefore, this study aims to determine the relationship between stress, emotional eating and food choices among university students in Malaysia during the Covid-19 pandemic.

\section{Methodology}

\section{Study design and subjects}


A web-based cross-sectional study was conducted during March to May 2020. Data collection was performed via Google Forms platform, with the questionnaire link being distributed online via emails and social networks. Students from a private university in Malaysia aged 18 and above were invited to participate. Students with a history of a chronic condition, on medications, and pregnant were excluded from this study. This study was approved by the University Science \& Engineering Research Ethics Committee. An online informed consent was obtained from each participant.

\section{Questionnaire and data collection}

The participants were instructed to complete a questionnaire consisting of four sections including the socio-demographic characteristics, Perceived Stress Scale, Semi-quantitative Food Frequency Questionnaire, and Emotional Appetite Questionnaire.

\section{Part A: Sociodemographic Characteristics and anthropometric assessment}

Sociodemographic data including the age, gender, ethnicity, current year of study, faculty of study course, dieting intention, smoking status and physical activity level were collected. In addition, participants were required to self-report their body weight measured in kilograms $(\mathrm{kg})$ and height measured in meters $(\mathrm{m})$. The body mass index (BMI) of the participants was calculated using the formula weight/height ${ }^{2}\left(\mathrm{~kg} / \mathrm{m}^{2}\right)$ and categorised into underweight $\left(<18.5 \mathrm{~kg} / \mathrm{m}^{2}\right)$, normal weight $\left(18.5-22.9 \mathrm{~kg} / \mathrm{m}^{2}\right)$, overweight $\left(23-27.4 \mathrm{~kg} / \mathrm{m}^{2}\right)$, and obese $\left(\geq 27.5 \mathrm{~kg} / \mathrm{m}^{2}\right)$ using the Asia-Pacific classification of BMI (World Health Organization, 2004).

\section{Part B: Perceived Stress Scale}

The stress intensity of the participants was measured using Cohen's Perceived Stress Scale (PSS-10) (Cohen, 1988). The questionnaire assessed the extent to which the participants found their lives uncontrollable in the past month, using a 5-point Likert scale (' $0=$ Never', ' $4=$ Very Often'). The four positively stated items (items 4,5,7, and 8) were reversed and all items were added up to obtain the total Perceived Stress Scale scores. The total scores ranged from 0 to 40, with higher scores indicating higher perceived stress levels. Participants with total scores of $\leq 20$ were classified as "low stress" while participants with scores $\geq 21$ were classified as "high stress". In this study, the Cronbach's alpha coefficient was 0.607 .

\section{Part C: Semi-quantitative Food Frequency Questionnaire}

The semi-quantitative food frequency questionnaire (SFFQ) was used to indicate the participants' usual frequency of consumption of 12 food groups including cereals, milk products, salad, cooked vegetables, fresh fruits, meat, fish, fast food, snacks, sweets or sugar, cakes or cookies and soft drinks (Mikolajczyk, El Ansari and Maxwell, 2009). Each food group was rated on a 5-point scale ("1= Never', ' $2=1-4$ times a month', ‘ $3=$ Several times a week', ‘ $4=$ Daily', and ' $5=$ Several times a day').

\section{Part D: Emotional Appetite Questionnaire}

The Emotional Appetite Questionnaire (EMAQ) was included to determine the participants' dietary patterns in response to 22 different emotions and situations including five positive emotions (e.g., "When you are happy"), nine negative emotions (e.g., "When you are sad"), three positive situations (e.g., "When engaged in an enjoyable hobby") and five negative situations (e.g., "When under pressure") (Geliebter \& Aversa, 2003). Each item was rated on a 9-point Likert scale ("1-4= Much less", " $5=$ The same", "6-9= Much more"). There were other optional responses, such as "not applicable" and "don't know", that were not included in the scoring. The mean scores for positive emotions (EMAQ-PE), negative emotions (EMAQ-NE), positive situations (EMAQ-PS) and negative situations (EMAQ-NS) were obtained. The EMAQ-PE and EMAQ-PS scores were then averaged to obtain the total positive scores (EMAQ-P) while the EMAQ-NE and EMAQ-NS scores were averaged to obtain the total negative scores (EMAQ-N). In this study, the Cronbach's alpha coefficients were 0.618 for EMAQ-P and 0.803 for EMAQ-N. 


\section{Statistical Analysis}

All analyses were performed using Statistical Package for the Social Sciences (SPSS) version 25. Descriptive statistics were computed using means and standard deviations (SD) for continuous variables and using numbers and percentages for categorical variables. Comparisons between numerical variables and genders and stress groups were performed using independent t-tests while comparison between numerical variables and body mass status was conducted using one-way ANOVA. A Chi-square test was used to compare means between nominal and ordinal variables. Pearson correlation test was conducted to identify the relationship between emotional appetite status, food consumption and BMI. The statistical significance level was set at $\mathrm{p}<0.05$.

\section{Result}

\section{Sociodemographic characteristics}

The sociodemographic characteristics of the participants are shown in Table 1. A total of 273 university students with 132 males and 141 females participated in this study. The prevalence of stress was $49.8 \%$. The students had a mean age of $20.91 \pm 1.55$ years. The age for high-stress group $(21.12 \pm 1.60$ years) was greater than the low-stress group $(20.70 \pm 1.47$ years) $(p<0.05)$. Almost half of the students (46\%) were third-year students. About $42 \%$ of the students were dieting and the majority of the students were sedentary. The mean BMI of the participants was $21.96 \pm 3.62 \mathrm{~kg} / \mathrm{m}^{2}$ and the majority of the students (54.9\%) were identified as normal weight. Around $31.9 \%$ of the participants were classified as overweight or obese.

Table 1: Sociodemographic characteristics of participants by stress intensity

\begin{tabular}{|c|c|c|c|c|}
\hline Variable & $\begin{array}{l}\text { Total } \\
(\mathrm{N}=273) \\
\mathrm{n}(\%)\end{array}$ & $\begin{array}{l}\text { Low stress } \\
(\mathrm{N}=137) \\
\mathrm{n}(\%)\end{array}$ & $\begin{array}{l}\text { High stress } \\
(\mathrm{N}=136) \\
\mathrm{n}(\%)\end{array}$ & p-value \\
\hline Gender & & & & 0.363 \\
\hline Male & $132(48.4)$ & $70(51.1)$ & $62(45.6)$ & \\
\hline Female & $141(51.6)$ & $67(48.9)$ & $74(54.4)$ & \\
\hline Age (years) $($ Mean \pm SD $)$ & $20.91 \pm 1.55$ & $20.70 \pm 1.47$ & $21.12 \pm 1.60$ & $0.026^{*}$ \\
\hline Age group (years) & & & & $0.020^{*}$ \\
\hline $16-18$ & $17(6.2)$ & $10(7.3)$ & $7(5.1)$ & \\
\hline $19-21$ & $171(62.6)$ & $95(69.3)$ & $76(55.9)$ & \\
\hline $22-25$ & $85(31.1)$ & $32(23.4)$ & $53(39.0)$ & \\
\hline Ethnicity & & & & 0.146 \\
\hline Malay & $37(13.6)$ & $15(10.9)$ & $22(16.2)$ & \\
\hline Chinese & $194(71.1)$ & $106(77.4)$ & $88(64.7)$ & \\
\hline Indian & $18(6.6)$ & $7(5.1)$ & $11(8.1)$ & \\
\hline Others & $24(8.8)$ & $9(6.6)$ & $15(11.0)$ & \\
\hline Year of study & & & & 0.491 \\
\hline Foundation & $18(6.6)$ & $10(7.3)$ & $8(5.9)$ & \\
\hline Year 1 & 48 (17.6) & $30(21.9)$ & $18(13.2)$ & \\
\hline Year 2 & $58(21.2)$ & $28(20.4)$ & $30(22.1)$ & \\
\hline Year 3 & $126(46.2)$ & $58(42.3)$ & $68(50.0)$ & \\
\hline Year 4 & $20(7.3)$ & $10(7.3)$ & $10(7.4)$ & \\
\hline $\mathrm{PhD}$ & $3(1.1)$ & $1(0.7)$ & $2(1.5)$ & \\
\hline Faculty & & & & 0.438 \\
\hline Arts and Social Sciences & $60(22.0)$ & $33(24.1)$ & 27 19.9) & \\
\hline Engineering & $73(26.7)$ & $39(28.5)$ & $34(25.0)$ & \\
\hline Science & $140(51.3)$ & $65(47.4)$ & $75(55.1)$ & \\
\hline Trying to lose weight & & & & 0.846 \\
\hline Yes & $114(41.8)$ & $58(42.3)$ & $56(41.2)$ & \\
\hline
\end{tabular}


Malaysian Journal of Social Sciences and Humanities (MJSSH), Volume 6, Issue 9, (page 335 - 346), 2021 DOI: https://doi.org/10.47405/mjssh.v6i9.983

\begin{tabular}{lclll} 
No & $159(58.2)$ & $79(57.7)$ & $80(58.8)$ & \\
Smoking status & & & & 0.527 \\
Smoker & $10(3.7)$ & $6(4.4)$ & $4(2.9)$ & \\
$\begin{array}{l}\text { Non-smoker } \\
\text { Physical activity }\end{array}$ & $263(96.3)$ & $131(95.6)$ & $132(97.1)$ & \\
Lightly active & $32(11.7)$ & $21(15.3)$ & $11(8.1)$ & 0.342 \\
Sedentary & $241(88.3)$ & $116(84.7)$ & $125(91.2)$ & \\
Height $(\mathbf{c m})($ Mean \pm SD) & $165.80 \pm 9.15$ & $166.19 \pm 9.37$ & $165.42 \pm 8.94$ & 0.488 \\
Weight $(\mathbf{k g})($ Mean \pm SD) & $60.89 \pm 13.28$ & $61.51 \pm 13.61$ & $60.26 \pm 12.95$ & 0.438 \\
BMI (kg/m $\mathbf{m}^{2}$ (Mean \pm SD) & $21.96 \pm 3.62$ & $22.16 \pm 6.92$ & $21.79 \pm 8.41$ & 0.758 \\
BMI status & & & & 0.397 \\
Underweight & $36(13.2)$ & $20(14.6)$ & $16(11.8)$ & \\
Normal & $150(54.9)$ & $69(50.4)$ & $81(59.6)$ & \\
Overweight & $66(24.2)$ & $38(27.7)$ & $28(20.6)$ & \\
Obese & $21(7.7)$ & $10(7.3)$ & $11(8.1)$ & \\
\hline
\end{tabular}

$* \mathrm{p}<0.05$

\section{Stress intensity and emotional appetite status}

The stress intensity and emotional appetite status of the participants are shown in Table 2 . The students had a mean perceived stress scale score of $20.61 \pm 6.45$ and females $(21.43 \pm 6.14)$ generally perceived higher stress than males $(19.73 \pm 6.67)(\mathrm{p}<0.05)$. Overall, a total of $49.8 \%$ of the participants were considered as high stress.

On the other hand, our results showed gender differences in the EMAQ score for negative emotion. A higher score in EMAQ indicates a tendency to eat more. Males $(4.54 \pm 1.02)$ had a higher tendency to eat more as compared to females $(4.27 \pm 1.20)$ in response to negative emotions $(\mathrm{p}<0.05)$. However, there were no statistically significant differences between male and female participants for other emotional appetite status.

Table 2: Stress intensity and emotional appetite status of participants

\begin{tabular}{lllll}
\hline Variable & $\begin{array}{l}\text { Total } \\
(\mathbf{N = 2 7 3 )} \\
\mathbf{n}(\%)\end{array}$ & $\begin{array}{l}\text { Male } \\
\mathbf{( N = 1 3 2 )} \\
\mathbf{n}(\%)\end{array}$ & $\begin{array}{l}\text { Female } \\
(\mathbf{N = 1 4 1}) \\
\mathbf{n}(\%)\end{array}$ & p-value \\
\hline $\begin{array}{l}\text { Perceived Stress Scale } \\
\text { Mean } \pm \text { SD) }\end{array}$ & $20.61 \pm 6.45$ & $19.73 \pm 6.67$ & $21.43 \pm 6.14$ & $0.029^{*}$ \\
$\begin{array}{l}\text { Stress level } \\
\text { Low stress }\end{array}$ & $137(50.2)$ & $70(53.0)$ & $67(47.5)$ & 0.363 \\
High stress & $136(49.8)$ & $62(47.0)$ & $74(52.5)$ & \\
Emotional Appetite Status & & & & \\
(Mean \pm SD) & & & & \\
Positive emotion & $5.69 \pm 0.91$ & $5.74 \pm 0.96$ & $5.65 \pm 0.87$ & 0.410 \\
Negative emotion & $4.40 \pm 1.12$ & $4.54 \pm 1.02$ & $4.27 \pm 1.20$ & $0.045^{*}$ \\
Positive situation & $5.63 \pm 1.18$ & $5.64 \pm 1.18$ & $5.63 \pm 1.18$ & 0.965 \\
Negative situation & $3.79 \pm 1.33$ & $3.86 \pm 1.24$ & $3.71 \pm 1.41$ & 0.341 \\
Total positive & $5.66 \pm 0.94$ & $5.69 \pm 0.97$ & $5.64 \pm 0.91$ & 0.672 \\
Total negative & $4.09 \pm 1.09$ & $4.20 \pm 0.94$ & $3.99 \pm 1.20$ & 0.104 \\
\hline
\end{tabular}

$* \mathrm{p}<0.05$

\section{Stress intensity and emotional appetite status by body mass status}

The stress intensity and emotional appetite status of the participants by body mass status are shown in Table 3. There were no significant differences between stress intensity of different body mass status. 
DOI: https://doi.org/10.47405/mjssh.v6i9.983

In terms of emotional appetite status, there were significant differences between different body mass status groups for negative emotion $(\mathrm{p}=0.052)$, negative situation $(\mathrm{p}<0.01)$, and total negative EMAQ scores $(\mathrm{p}<0.01)$. Tukey post hoc test reported that obese participants scored significantly higher than underweight participants on the negative situation (obese: $4.55 \pm 1.68$; underweight: $3.32 \pm 1.19 ; \mathrm{p}<0.01$ ) and total negative EMAQ scores (obese: $4.67 \pm 1.42$; underweight: $3.65 \pm 0.95 ; \mathrm{p}<0.01$ ).

Table 3: Stress intensity and emotional appetite status of participants by body mass status

\begin{tabular}{|c|c|c|c|c|c|}
\hline Variable & $\begin{array}{l}\text { Underweight } \\
(\mathrm{N}=36) \\
\mathrm{n}(\%)\end{array}$ & $\begin{array}{l}\text { Normal } \\
(\mathrm{N}=150) \\
\mathrm{n}(\%)\end{array}$ & $\begin{array}{l}\text { Overweight } \\
(\mathrm{N}=66) \\
\mathrm{n}(\%)\end{array}$ & $\begin{array}{l}\text { Obese } \\
(\mathrm{N}=21) \\
\mathrm{n}(\%)\end{array}$ & p-value \\
\hline $\begin{array}{l}\text { Perceived Stress Scale } \\
(\text { Mean } \pm \text { SD) }\end{array}$ & $20.11 \pm 4.86$ & $21.03 \pm 6.73$ & $20.00 \pm 6.75$ & $20.38 \pm 6.01$ & 0.689 \\
\hline \multicolumn{6}{|l|}{ Stress level } \\
\hline Low stress & $20(55.6)$ & $69(46.0)$ & $38(57.6)$ & $10(47.6)$ & 0.397 \\
\hline High stress & $16(44.4)$ & $81(54.0)$ & $28(42.4)$ & $11(52.4)$ & \\
\hline \multicolumn{6}{|l|}{$\begin{array}{l}\text { Emotional appetite } \\
\text { status (Mean } \pm \text { SD) }\end{array}$} \\
\hline Positive emotion & $5.52 \pm 1.06$ & $5.70 \pm 0.81$ & $5.71 \pm 1.02$ & $5.83 \pm 0.98$ & 0.601 \\
\hline Negative emotion & $3.98 \pm 1.01$ & $4.42 \pm 1.12$ & $4.44 \pm 1.08$ & $4.79 \pm 1.29$ & 0.052 \\
\hline Positive situation & $5.49 \pm 1.27$ & $5.63 \pm 1.12$ & $5.61 \pm 1.27$ & $5.94 \pm 1.22$ & 0.591 \\
\hline Negative situation & $3.32 \pm 1.19$ & $3.77 \pm 1.30$ & $3.84 \pm 1.26$ & $4.55 \pm 1.68$ & $0.009 * *$ \\
\hline Total positive & $5.51 \pm 1.11$ & $5.67 \pm 0.85$ & $5.66 \pm 1.01$ & $5.88 \pm 1.04$ & 0.536 \\
\hline Total negative & $3.65 \pm 0.95$ & $4.10 \pm 1.05$ & $4.14 \pm 1.05$ & $4.67 \pm 1.42$ & $0.007 * *$ \\
\hline
\end{tabular}

\section{Frequency of food consumption by gender and stress intensity}

The consumption of the twelve food groups stratified by gender and stress group is shown in Table 4 . In Males, high-stress group (2.95 \pm 0.98$)$ was found to consume more sweets than the low-stress group $(2.60 \pm 0.84)(\mathrm{p}<0.05)$. In females, the frequency of milk product and fresh fruit intakes of the lowstress group (3.01 \pm 0.75 and $3.22 \pm 0.85$, respectively) was higher than the high-stress group $(2.70 \pm 0.79$ and $2.97 \pm 0.71$, respectively) $(\mathrm{p}<0.05)$. On the other hand, the intake frequency of sweets or sugar and cakes or cookies were higher in the female high-stress group ( $2.95 \pm 0.89$ and $2.53 \pm 0.73$, respectively) than the low-stress group ( $2.60 \pm 0.82$ and $2.28 \pm 0.60$, respectively) $(\mathrm{p}<0.05)$.

Table 4: Frequency of food consumption by gender and stress intensity

\begin{tabular}{lllllll}
\hline & Male & \multicolumn{5}{c}{ Female } \\
\cline { 2 - 7 } Food group & $\begin{array}{l}\text { Low stress } \\
(\mathbf{N = 7 0 )} \\
\text { Mean } \pm \text { SD }\end{array}$ & $\begin{array}{l}\text { High } \\
\text { stress } \\
(\mathbf{N = 6 2}) \\
\text { Mean } \pm \text { SD }\end{array}$ & $\begin{array}{l}\text { p- } \\
\text { value }\end{array}$ & $\begin{array}{l}\text { Low stress } \\
(\mathbf{N = 6 7 )} \\
\text { Mean } \pm \text { SD }\end{array}$ & $\begin{array}{l}\text { High } \\
\text { stress } \\
(\mathbf{N = 7 4 )} \\
\text { Mean } \pm \text { SD }\end{array}$ & $\begin{array}{l}\text { p- } \\
\text { value }\end{array}$ \\
\hline Cereal/cereal products & $2.29 \pm 0.97$ & $2.29 \pm 0.98$ & 0.978 & $2.51 \pm 0.98$ & $2.30 \pm 0.84$ & 0.171 \\
Milk products & $2.91 \pm 0.93$ & $2.98 \pm 0.97$ & 0.674 & $3.01 \pm 0.75$ & $2.70 \pm 0.79$ & $0.018^{*}$ \\
Salad & $2.11 \pm 0.83$ & $2.37 \pm 0.98$ & 0.109 & $2.18 \pm 0.76$ & $2.19 \pm 0.75$ & 0.937 \\
Cooked vegetables & $3.41 \pm 1.07$ & $3.61 \pm 1.11$ & 0.297 & $3.87 \pm 0.81$ & $3.70 \pm 0.82$ & 0.240 \\
Fresh fruits & $2.97 \pm 0.83$ & $2.90 \pm 0.92$ & 0.655 & $3.22 \pm 0.85$ & $2.97 \pm 0.71$ & $0.046^{*}$ \\
Meat & $4.04 \pm 0.84$ & $4.16 \pm 0.73$ & 0.392 & $3.73 \pm 0.81$ & $3.50 \pm 1.11$ & 0.158 \\
Fish & $2.89 \pm 0.86$ & $2.89 \pm 0.87$ & 0.993 & $2.79 \pm 0.86$ & $2.64 \pm 0.77$ & 0.258 \\
Fast food & $2.39 \pm 0.57$ & $2.58 \pm 0.78$ & 0.101 & $2.24 \pm 0.61$ & $2.30 \pm 0.59$ & 0.563 \\
Snacks & $2.56 \pm 0.75$ & $2.66 \pm 0.83$ & 0.451 & $2.63 \pm 0.78$ & $2.76 \pm 0.89$ & 0.359 \\
Sweets/sugar & $2.60 \pm 0.84$ & $2.95 \pm 0.98$ & $0.028^{*}$ & $2.60 \pm 0.82$ & $2.95 \pm 0.89$ & $0.017^{*}$ \\
Cakes/cookies & $2.33 \pm 0.81$ & $2.34 \pm 0.70$ & 0.939 & $2.28 \pm 0.60$ & $2.53 \pm 0.73$ & $0.031^{*}$
\end{tabular}


DOI: https://doi.org/10.47405/mjssh.v6i9.983

Soft drinks

$2.37 \pm 0.90$

$2.56 \pm 0.92$

0.226

$1.85 \pm 0.68$

$2.05 \pm 0.83$

0.115

$* \mathrm{p}<0.05$

\section{Frequency of food intake in relation to positive and negative emotions}

The correlations between positive and negative emotional appetite status and all twelve food groups are shown in Table 5. Students with higher negative emotion scores were associated with lower intakes of cooked vegetables $(r=-0.133 ; p<0.05)$ whereas students with higher positive emotion scores were associated with higher intakes of fast food $(r=0.208 ; \mathrm{p}<0.001)$, sweets $(r=0.139 ; \mathrm{p}<0.05)$ and cakes $(\mathrm{r}=0.139 ; \mathrm{p}<0.05)$.

Table 5: Association between the frequency of food consumption and emotional appetite status

\begin{tabular}{lllll}
\hline \multirow{2}{*}{ Food Group } & \multicolumn{3}{l}{ Emotional appetite status } & \\
\cline { 2 - 5 } & Positive & & Negative & \\
\cline { 2 - 5 } & $\mathbf{r}$ & $\mathbf{p}$-value & $\mathbf{r}$ & $\mathbf{p}$-value \\
\hline Cereal/cereal products & 0.063 & 0.297 & 0.099 & 0.101 \\
Milk products & 0.112 & 0.066 & 0.085 & 0.161 \\
Salad & 0.014 & 0.813 & 0.055 & 0.367 \\
Cooked vegetables & -0.061 & 0.319 & -0.133 & $0.028^{*}$ \\
Fresh fruits & 0.013 & 0.829 & 0.003 & 0.963 \\
Meat & 0.109 & 0.072 & -0.019 & 0.754 \\
Fish & -0.028 & 0.640 & 0.069 & 0.253 \\
Fast food & 0.208 & $0.001^{* *}$ & 0.055 & 0.365 \\
Snacks & 0.026 & 0.666 & 0.085 & 0.159 \\
Sweets/sugar & 0.139 & $0.021^{*}$ & -0.025 & 0.686 \\
Cakes/cookies & 0.139 & $0.021^{*}$ & 0.022 & 0.720 \\
Soft drinks & 0.109 & 0.072 & 0.098 & 0.106 \\
\hline
\end{tabular}

$* \mathrm{p}<0.05, * * \mathrm{p}<0.01$

\section{Association between emotional appetite status and BMI}

The correlation between BMI and emotional appetite status is shown in Table 6. There was a positive correlation ( $r=0.134)$ between BMI and negative emotion, which was significant $(\mathrm{p}<0.05)$. In addition, the negative situation was positively and significantly correlated with BMI $(r=0.161 ; p<0.01)$. Also, the total negative EMAQ scores were positively and significantly correlated with BMI $(r=0.168$; $\mathrm{p}<0.01)$.

Table 6: Correlation between BMI and emotional appetite status

\begin{tabular}{lll}
\hline Emotional appetite status & Correlation coefficient, $\mathbf{r}$ & p-value \\
\hline Positive emotion & 0.045 & 0.460 \\
Negative emotion & 0.134 & $0.027^{*}$ \\
Positive situation & 0.048 & 0.429 \\
Negative situation & 0.161 & $0.008^{* *}$ \\
Total positive & 0.052 & 0.393 \\
Total negative & 0.168 & $0.006^{* *}$ \\
\hline
\end{tabular}

$* \mathrm{p}<0.05, * * \mathrm{p}<0.01$

\section{Discussion}

The present study examined the relationship between stress, emotional eating, and food consumption among university students in Malaysia during the Covid-19. In this study, almost half (49.8\%) of the private university students were under high levels of stress during the Covid-19 pandemic. The result 
outweighed the previous report on stress among private university students, which reported a prevalence of $40 \%$ (Cheng \& Kamil, 2020). Our finding is consistent with the past study showing high stress levels among university students during the Covid-19 pandemic (Cao et al., 2020). The high stress level could be due to the huge changes to their daily life such as lack of social life, social distancing, online teachings, new assessment methods and uncertainty in their future career (Cao et al., 2020; Aristovnik et al., 2020).

We found out that female university students perceived higher stress than their male counterparts during the Covid-19. These findings were in line with previous studies that revealed higher levels of stress among females university students in Saudi Arabia (Halboub et al., 2018) and Kenya (Misigo, 2015). This stems from the fact that women tended to experience more chronic negative circumstances than men (Nolen-Hoeksema, Larson \& Grayson, 1999). In addition, women were more likely to ruminate during stress and had a lower sense of mastery over their lives (Nolen-Hoeksema, Larson \& Grayson, 1999).

Our study showed that high perceived stress was associated with increased consumption of sweets during the Covid-19. In particular, female participants consumed more sweets and cakes but less fresh fruits and milk when stressed. The association between perceived stress and increased sweets and cakes intakes were also documented in college women (Kandiah et al., 2006) and undergraduates students (Oliver \& Wardle, 1999). Besides, increased palatable food intake was observed in highstress emotional eaters, especially in women (Oliver, Wardle \& Gibson, 2000). Furthermore, a minireview on the effect of stress on dietary behaviours among university students concluded that female students tended to shift their preference to unhealthy foods during stress (Elshurbjy \& Ellulu, 2017). This is because consuming palatable foods triggers increased dopamine secretion and decreases activity in the central stress system and therefore attenuates the hypothalamic-pituitary-adrenal axis responses (Ulrich-Lai, 2016; Yau \& Potenza, 2013). That would suggest that, prolonged and repeated perceived stress can over time increase one's energy intake and eventually results in weight gain and obesity.

Also, our finding, which showed a negative association between stress and fresh fruit intake was consistent with another study conducted in three European countries (Mikolajczyk, El Ansari \& Maxwell, 2009). In their study, females had a higher frequency of sweet intake and a lower frequency of fruit intake during stress (Mikolajczyk, El Ansari \& Maxwell, 2009). Besides, a study conducted among university students in Egypt showed a negative association between perceived stress scores and fruit and vegetable intakes (El Ansari and Berg-Beckhoff, 2015). The reduction in fresh fruit and milk intakes in females can be explained by the findings of Zellner et al. (2006) where stress caused transitions in food preferences from healthy, nutrient-rich food to less healthy high caloric food. Taken together, these findings indicate that perceived stress affects dietary behaviour and leads to poor dietary choices by increasing the selection of high palatability and energy-dense snack foods, particularly in female university students. This may be influenced by the habit of using eating as a coping mechanism to improve and deal with distress (Solomon, 2001).

Emotional eating refers to the tendency of overeating in response to emotions instead of physical hunger (van Strien, 2018). We found out that males were more likely to overeat when experiencing negative emotions compared to females. Our findings were supported by a cross-sectional survey in Turkey which demonstrated that men tended to overeat during negative situations (Bilici et al., 2020). Thus, we can conclude that men experienced more emotional eating during negative emotions or situations as compared to women. Females generally report higher levels of body size dissatisfaction and a greater desire to be thin than males due to social norms (Thompson, 2015). Therefore, women tended to control their diets to maintain body shape and this results in a lower prevalence of emotional eating than men, even during negative situations.

Theoretical frameworks of eating behaviours suggested that people were more likely to consume unhealthy foods in response to negative affect (Goldschmidt et al., 2014; Jansen et al., 2008; Polivy \& Herman, 1993) while consuming healthy foods in response to positive affect (Smith et al., 2018; White, Horwath \& Conner, 2013). However, our study found a positive correlation between total 
positive EMAQ scores and the consumption of fast food, sweets, and cakes. This is in line with the study by Evers et al. (2013) which reported higher unhealthy food intake during positive emotions compared to negative emotions. Also, during positive emotions, the participants snacked more frequently than during negative emotions (Evers et al., 2013). A meta-analysis also found that individuals tended to consume more sweet and savoury foods after positive mood induction (Cardi, Leppanen and Treasure, 2015). On the other hand, Arshust et al. (2018) revealed a higher consumption of sweets but a lower consumption of fast food when they were experiencing positive emotions. This is because positive emotions such as joy and happiness were reported to affect palatable food intake by activating the hedonic motivational pathways in healthy people (Macht, 1999). The experimentally induced positive mood has been shown to enhance pleasantness and amplify the motivational salience of sweet snacks (Macht, Roth \& Ellgring, 2002).

On the other hand, a negative correlation was observed between total negative EMAQ scores and cooked vegetable intake. The decreased cooked vegetable intake in response to negative emotions in this study is aligned with the previous study which found lower quality of diets during negative emotions in women of lower educational attainment (Jarman et al., 2012). The reason for that might be, negative emotions would affect decision making and often lead to poor decisions. Taken together, our study showed that, during positive emotions, participants tended to consume more palatable foods while during negative emotions, participants tended to consume less healthy foods.

In the present study, negative emotion scores, negative situation scores and total negative EMAQ scores were positively correlated with BMI. In particular, obese people had higher negative emotion scores, negative situation scores, and total negative EMAQ scores than underweight people. Obese individuals were more likely to overeat after experiencing unpleasant feelings during negative emotions and/or negative situations compared to underweight people. This is in line with the validated study of Nolan, Halperin and Geliebter (2010), which found that negative EMAQ scores were correlated with BMI. These findings also were consistent with the study conducted by Geliebter and Aversa (2003), where overweight participants reported eating more than normal-weight and underweight participants when facing negative emotions or situations. Also, Bilici et al. (2020) reported a positive association between BMI groups and negative emotions, negative situations, and total negative EMAQ scores. This is due to the fact that overweight individuals exhibited less effective coping skills in times of negative emotions, reduced their ability to resist eating, and therefore leading them to eat emotionally (Ozier et al., 2008). Overweight and obese individuals, when experiencing negative emotions, would consume more energy-dense palatable foods to reduce the negative state (Yau \& Potenza, 2013).

Interestingly, there were no significant relationships between positive EMAQ scores and BMI despite the association between positive EMAQ scores and palatable food intake, including fast food, sweets and cake intake. Although previous studies reported inverse relationships between positive EMAQ scores and BMI (Geliebter \& Aversa, 2003; Nolan, Halperin \& Geliebter, 2010), our findings were supported by the study conducted by Bilici et al. (2020) where they found no correlation between BMI groups and positive emotions, positive situations and total positive EMAQ scores. Besides, van Strien, Donker, and Ouwens (2016) also found no significant differences in the desire to eat in response to positive emotions between overweight and normal-weight women. These showed that negative emotions, but not positive emotions, resulted in overeating in overweight or obese individuals. This is because obese individuals were more sensitive to negative emotions (Sinha \& Jastreboff, 2013) and tended to have higher levels of depression, lower self-esteem, and higher perceived stress (Oh et al., 2016).

There were limitations in this study despite all the findings being discussed. Firstly, the findings on stress, emotions, and food intake using self-reported questionnaires which mainly rely on personal recall and honesty may not be accurate and reliable. Self-reported food frequency questionnaire might result in under- and over-reporting (Maurer et al., 2006). Secondly, the causality of stress and emotional behaviour on food choices was hard to be established because of the cross-sectional design of the study. Lastly, other possible factors that may affect the eating behaviour of the participants 
including the availability of food, type of stressors, living situation, dietary restraint level, and socioeconomic status of participants were not included in this study.

\section{Conclusion}

In conclusion, the prevalence of stress among private university students were at an alarming rate, which required attention. The key finding in this study was that stress, as well as positive and negative emotions, indeed alter eating behaviours, redirecting food choices from healthy foods to foods with greater palatability and energy value during the Covid-19. In particular, stress and positive emotions significantly increased the consumption of palatable foods. Also, negative emotions were associated with increased Body Mass Index among students. Males and obese individuals particularly were more likely to engage in emotional eating after experiencing negative emotions compared to females and underweight individuals. These should not be taken lightly as unhealthy eating behaviour over a long period will lead to overweight and obesity and impose negative health consequences in later life. Further studies should include other possible contributors to stress and eating behaviour, especially dietary restraint level. A diet diary could also be detrimental to better understand the effect of stress and emotions on dietary intake. Finally, stress management interventions and nutrition education should be implemented to reduce stress and overcome stress-induced eating behaviour and emotional eating among private university students during the Covid-19 pandemic.

\section{References}

Abdel Wahed, W. Y. \& Hassan, S. K. (2017) Prevalence And Associated Factors Of Stress, Anxiety And Depression Among Medical Fayoum University Students. Alexandria Journal Of Medicine, 53, 77-84.

Aristovnik, A., Keržič, D., Ravšelj, D., Tomaževič, N., Umek, L. (2020). Impacts of the COVID-19 Pandemic on Life of Higher Education Students: A Global Perspective. Sustainability, 12, 8438.

Arnow, B., Kenardy, J. \& Agras, W. S. (1995) The Emotional Eating Scale: The Development Of A Measure To Assess Coping With Negative Affect By Eating. International Journal Of Eating Disorders, 18, 79-90.

Barrington, W. E., Beresford, S. A. A., Mcgregor, B. A. \& White, E. (2014) Perceived Stress And Eating Behaviors By Sex, Obesity Status, And Stress Vulnerability: Findings From The Vitamins And Lifestyle (Vital) Study. Journal Of The Academy Of Nutrition And Dietetics, 114, 1791-1799.

Bayram, N. \& Bilgel, N. (2008) The Prevalence And Socio-Demographic Correlations Of Depression, Anxiety And Stress Among A Group Of University Students. Soc Psychiatry Psychiatr Epidemiol, 43, 667-72.

Biasi, V. \& Bonaiuto, P. (2014) Negative Emotions And Defence Mechanisms In Obese People. Psychology, 5(18), 1979-1988.

Bilici, S., Ayhan, B., Karabudak, E. \& Koksal, E. (2020) Factors Affecting Emotional Eating And Eating Palatable Food In Adults. Nutrition Research And Practice, 14, 70.

Cao,W., Fang, Z., Hou, G., Han, M., Xu, X., Dong, J., Zheng, J. (2020) The psychological impact of the COVID-19 epidemic on college students in China. J. Psychiatry Res. 287, 112934.

Cardi, V., Leppanen, J. \& Treasure, J. (2015) The Effects Of Negative And Positive Mood Induction On Eating Behaviour: A Meta-Analysis Of Laboratory Studies In The Healthy Population And Eating And Weight Disorders. Neuroscience \& Biobehavioral Reviews, 57, 299-309.

Cheng, S. H. \& Kamil, M. (2020) Stress And Food Intake Among University Students - Is There A Relationship? Sains Malaysiana, 49, 121-128.

Cohen, S. (1988) Perceived Stress In A Probability Sample Of The United States. The Social Psychology Of Health. Thousand Oaks, Ca, Us: Sage Publications, Inc.

El Ansari, W. \& Berg-Beckhoff, G. (2015) Nutritional Correlates Of Perceived Stress Among University Students In Egypt. Int J Environ Res Public Health, 12, 14164-76. 
Elshurbjy, A. \& Ellulu, M. S. (2017) Association Between Stress And Dietary Behaviors Among University Students: Mini-Review. Medical And Clinical Archives, 1.

Evers, C., Adriaanse, M., Ridder, D. \& Huberts, J. (2013) Good Mood Food: Positive Emotion As A Neglected Trigger For Food Intake. Appetite, 68.

Ganley, R. M. (1989) Emotion And Eating In Obesity: A Review Of The Literature. International Journal Of Eating Disorders, 8, 343-361.

Geliebter, A. \& Aversa, A. (2003) Emotional Eating In Overweight, Normal Weight, And Underweight Individuals. Eating Behaviors, 3, 341-347.

Goldschmidt, A. B., Crosby, R. D., Engel, S. G. et al. (2014) Affect And Eating Behavior In Obese Adults With And Without Elevated Depression Symptoms. Int J Eat Disord, 47, 281-6.

Halboub, E., Alhajj, M. N., Alkhairat, A. M., Sahaqi, A.-A. M. \& Quadri, M. F. A. (2018) Perceived Stress Among Undergraduate Dental Students In Relation To Gender, Clinical Training And Academic Performance. Acta Stomatologica Croatica, 52, 37-45.

Jansen, A., Vanreyten, A., van Balveren, T., Roefs, A., Nederkoorn, C. \& Havermans, R. (2008) Negative Affect And Cue-Induced Overeating In Non-Eating Disordered Obesity. Appetite, 51, 556-62.

Jarman, M., Lawrence, W., Ntani, G. et al. (2012) Low Levels Of Food Involvement And Negative Affect Reduce The Quality Of Diet In Women Of Lower Educational Attainment. J Hum Nutr Diet, 25, 444-52.

Kandiah, J., Yake, M., Jones, J. \& Meyer, M. (2006) Stress Influences Appetite And Comfort Food Preferences In College Women. Nutrition Research, 26, 118-123.

Khubchandani, J., Kandiah, J., Saiki, D. (2020) The COVID-19 Pandemic, Stress, and Eating Practices in the United States. Eur. J. Investig. Health Psychol. Educ. 10, 950-956.

Laitinen, J., Ek, E. \& Sovio, U. (2002) Stress-Related Eating And Drinking Behavior And Body Mass Index And Predictors Of This Behavior. Prev Med, 34, 29-39.

Lindeman, M. \& Stark, K. (2001) Emotional Eating And Eating Disorder Psychopathology. Eat Disord, 9, 251-9.

Macht, M. (1999) Characteristics Of Eating In Anger, Fear, Sadness And Joy. Appetite, 33 (1), 129139.

Macht, M., Roth, S. \& Ellgring, H. (2002) Chocolate Eating In Healthy Men During Experimentally Induced Sadness And Joy. Appetite, 39, 147-58.

Macht, M. \& Simons, G. (2000) Emotions And Eating In Everyday Life. Appetite, 35, 65-71.

Maurer, J., Taren, D. L., Teixeira, P. J. et al. (2006) The Psychosocial And Behavioral Characteristics Related To Energy Misreporting. Nutrition Reviews, 64, 53-66.

Mikolajczyk, R. T., El Ansari, W. \& Maxwell, A. E. (2009) Food Consumption Frequency And Perceived Stress And Depressive Symptoms Among Students In Three European Countries. Nutrition Journal, 8, 31.

Monroe, S. M. \& Cummins, L. F. (2015) Stress: Psychological Perspectives. In: Wright, J. D. (Ed.) International Encyclopedia Of The Social \& Behavioral Sciences (Second Edition). Oxford: Elsevier.

Muna, S. \& Atinkut, Z. (2018) Prevalence And Associated Factors Of Stress Among Undergraduate Students In Ambo University: Implication For Intervention. International Journal Of Psychology And Counselling, 10, 29-39.

Nelson, M. C., Story, M., Larson, N. I., Neumark-Sztainer, D. \& Lytle, L. A. (2008) Emerging Adulthood And College-Aged Youth: An Overlooked Age For Weight-Related Behavior Change. Obesity (Silver Spring), 16, 2205-11.

Nguyen-Michel, S. T., Unger, J. B. \& Spruijt-Metz, D. (2007) Dietary Correlates Of Emotional Eating In Adolescence. Appetite, 49, 494-499.

Nolan, L. J., Halperin, L. B. \& Geliebter, A. (2010) Emotional Appetite Questionnaire. Construct Validity And Relationship With BMI. Appetite, 54, 314-9.

Nolen-Hoeksema, S., Larson, J. \& Grayson, C. (1999) Explaining The Gender Difference In Depressive Symptoms. J Pers Soc Psychol, 77, 1061-72.

Oh, Y., Hass, N. C. \& Lim, S.-L. (2016) Body Weight Can Change How Your Emotions Are Perceived. PloS One, 11(11), e0166753.

Oliver, G. \& Wardle, J. (1999) Perceived Effects Of Stress On Food Choice. Physiology \& Behavior, 66, 511-515. 
Oliver, G., Wardle, J. \& Gibson, E. L. (2000) Stress And Food Choice: A Laboratory Study. Psychosomatic Medicine, 62, 853-865.

Ozier, A. D., Kendrick, O. W., Leeper, J. D., Knol, L. L., Perko, M. \& Burnham, J. (2008) Overweight And Obesity Are Associated With Emotion- And Stress-Related Eating As Measured By The Eating And Appraisal Due To Emotions And Stress Questionnaire. J Am Diet Assoc, 108, 4956.

Pfefferbaum, B.\& North, C.S. (2020) Mental Health and the Covid-19 Pandemic. N. Engl. J. Med., 383, 510-512.

Polivy, J. \& Herman, C. P. (1993) Etiology Of Binge Eating: Psychological Mechanisms. Binge Eating: Nature, Assessment, And Treatment. New York, Ny, US: Guilford Press.

Misigo, B. L. (2015) Gender Difference In The Perceived Level Of Stress And Coping Strategies Among University Students In Kenya: A Case Of Public Universities. International Academic Journal Of Social Sciences And Education, 1, 44-52.

Muharrani, N. P., Achmad, E. \& Sudiarti, T. (2018) Effects Of Restrained, External, And Emotional Eating Styles On Weight Gain Among Female Students At Faculty Of Public Health, Universitas Indonesia. Kne Life Sciences, 4, 8.

Reddy, K., Menon, K. R. \& Thattil, A. (2018) Academic Stress And Its Sources Among University Students. Biomedical And Pharmacology Journal, 11, 531-537.

Sinha, R. \& Jastreboff, A. M. (2013) Stress As A Common Risk Factor For Obesity And Addiction. Biol Psychiatry, 73, 827-35.

Smith, K. E., Mason, T. B., Crosby, R. D. et al. (2018) State And Trait Positive And Negative Affectivity In Relation To Restraint Intention And Binge Eating Among Adults With Obesity. Appetite, 120, 327-334.

Solomon, M. R. (2001) Eating As Both Coping And Stressor In Overweight Control. J Adv Nurs, 36, 563-72.

Thompson, S. (2015) Gender And Racial Differences In Emotional Eating, Food Addiction Symptoms, And Body Weight Satisfaction Among Undergraduates. Journal Of Diabetes And Obesity, 2, 1-6.

Torres, S. J. \& Nowson, C. A. (2007) Relationship Between Stress, Eating Behavior, And Obesity. Nutrition, 23, 887-894.

Ulrich-Lai, Y. M. (2016) Self-Medication With Sucrose. Current Opinion In Behavioral Sciences, 9, 78-83.

van Strien, T. (2018) Causes Of Emotional Eating And Matched Treatment Of Obesity. Current Diabetes Reports, 18, 35-35.

van Strien, T., Donker, M. H. \& Ouwens, M. A. (2016) Is Desire To Eat In Response To Positive Emotions An 'Obese' Eating Style: Is Kummerspeck For Some People A Misnomer? Appetite, 100, 225-235.

Vollrath, M. (2001) Personality And Stress. Scandinavian Journal Of Psychology, 42, 335-347.

Wallis, D. J. \& Hetherington, M. M. (2004) Stress And Eating: The Effects Of Ego-Threat And Cognitive Demand On Food Intake In Restrained And Emotional Eaters. Appetite, 43, 39-46.

Wardle, J., Steptoe, A., Oliver, G. \& Lipsey, Z. (2000) Stress, Dietary Restraint And Food Intake. Journal Of Psychosomatic Research, 48, 195-202.

White, B. A., Horwath, C. C. \& Conner, T. S. (2013) Many Apples A Day Keep The Blues Away-Daily Experiences Of Negative And Positive Affect And Food Consumption In Young Adults. Br J Health Psychol, 18, 782-98.

Wong, J. G. W. S., Cheung, E. P. T., Chan, K. K. C., Ma, K. K. M. \& Tang, S. W. (2006) Web-Based Survey Of Depression, Anxiety And Stress In First-Year Tertiary Education Students In Hong Kong. Australian \& New Zealand Journal Of Psychiatry, 40, 777-782.

World Health Organization. (2004) Appropriate body-mass index for Asian populations and its implications for policy and intervention strategies. The Lancet, 363, 157-163.

Yau, Y. H. C. \& Potenza, M. N. (2013) Stress And Eating Behaviors. Minerva Endocrinologica, 38, 255-267.

Zellner, D.A., Loaiza, S., Gonzalez Z., Pita, J., Morales, J., Pecora, D. and Wolf, A. (2006) Food Selection Changes Under Stress. Physiology \& Behaviour, 87(4), 789-93. 